\title{
SIGNIFICANT PERFORMANCE VARIATION AMONG PCR SYSTEMS IN DIAGNOSING CONGENITAL TOXOPLASMOSIS IN SÃO PAULO, BRAZIL: ANALYSIS OF 467 AMNIOTIC FLUID SAMPLES
}

\author{
Thelma Suely Okay, ${ }^{\mathrm{I}}$ Lidia Yamamoto, ${ }^{\mathrm{I}}$ Léa Campos Oliveira, ${ }^{\mathrm{I}}$ Erika Regina

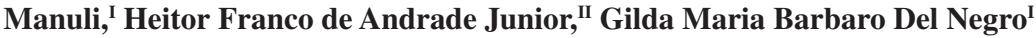

doi: $10.1590 / \mathbf{S 1 8 0 7 - 5 9 3 2 2 0 0 9 0 0 0 3 0 0 0 0 4}$

\begin{abstract}
Okay TS, Yamamoto L, Oliveira LC, Manuli ER, Andrade Jr. HF, Del Negro GMB. Significant performance variation among PCR systems in diagnosing congenital toxoplasmosis in São Paulo, Brazil: analysis of 467 amniotic fluid samples. Clinics. 2009;64(3):171-6.
\end{abstract}

INTRODUCTION: Performance variation among PCR systems in detecting Toxoplasma gondii has been extensively reported and associated with target genes, primer composition, amplification parameters, treatment during pregnancy, host genetic susceptibility and genotypes of different parasites according to geographical characteristics.

PATIENTS: A total of 467 amniotic fluid samples from T. gondii IgM- and IgG-positive Brazilian pregnant women being treated for 1 to 6 weeks at the time of amniocentesis (gestational ages of 14 to 25 weeks).

METHODS: One nested-B1-PCR and three one-round amplification systems targeted to rDNA, AF146527 and the B1 gene were employed.

RESULTS: Of the 467 samples, 189 (40.47\%) were positive for one-round amplifications: 120 (63.49\%) for the B1 gene, 24 (12.69\%) for AF146527, 45 (23.80\%) for both AF146527 and the B1 gene, and none for rDNA. Fifty previously negative oneround PCR samples were chosen by computer-assisted randomization analysis and re-tested (nested-B1-PCR), during which nine additional cases were detected (9/50 or $18 \%)$.

DISCUSSION: The B1 gene PCR was far more sensitive than the AF146527 PCR, and the rDNA PCR was the least effective even though the rDNA had the most repetitive sequence. Considering that the four amplification systems were equally affected by treatment, that the amplification conditions were optimized for the target genes and that most of the primers have already been reported, it is plausible that the striking differences found among PCR performances could be associated with genetic diversity in patients and/or with different Toxoplasma gondii genotypes occurring in Brazil.

CONCLUSION: The use of PCR for the diagnosis of fetal Toxoplasma infections in Brazil should be targeted to the B1 gene when only one gene can be amplified, preferably by nested amplification with primers B22/B23.

KEYWORDS: Toxoplasma gondii; Toxoplasmosis; Congenital infection; PCR; Molecular diagnosis.

'Laboratory of Medical Investigation (LIM 36), Department of Pediatrics, Instituto da Criança, Faculdade de Medicina da Universidade de São Paulo - São Paulo/SP, Brazil.

"Department of Pathology, Faculdade de Medicina da Universidade de São Paulo - São Paulo/SP, Brazil.

Tel.: 55113069.8606

Email: thelma.okay@icr.usp.br

Received for publication on August 20, 2008

Accepted for publication on November 01, 2008

\section{INTRODUCTION}

Toxoplasmosis causes an endemic worldwide infection that is asymptomatic in the majority of patients, with the exception of pregnant women and immunosuppressed individuals. Primary maternal Toxoplasma infection exposes the fetus to the risk of parasite transmission, leading to severe congenital toxoplasmosis, depending 
on host susceptibility, date of transmission, prescription of anti-parasite treatment, parasite burden and parasite genotype. ${ }^{1-5}$ Although conventional laboratory diagnosis is still based on serologic parameters such as the presence of IgM and IgG anti-Toxoplasma and parasite isolation in mice or culture, the polymerase chain reaction (PCR) has been performed since the 1990s in an attempt to improve laboratory diagnosis sensitivity. There is, however, no consensus regarding the most effective amplification system for this purpose. ${ }^{6-13}$ The efficiency of PCR targets was tested in controlled studies, and the disease has been associated with three main clonal lineages of $T$. gondii, with type I corresponding to more pathogenic strains and types II and III to less pathogenic ones. There is a high prevalence of genotype II in congenital infection, which, has not yet been described in South American human infections. ${ }^{14}$ The present study aimed to analyze the performance of three one-round PCRs targeted to rDNA, AF146527 and the B1 gene in the amniotic fluid of 467 pregnant Brazilian women who seroconverted during the first or early second trimester of pregnancy and were treated for acute toxoplasmosis until labor. Furthermore, the performance of a nested-B1-PCR was evaluated in 50 previously negative $T$. gondii oneround amplifications.

\section{PATIENTS AND METHODS}

PATIENTS: This research was approved by the Institutional Ethics Committee (CAPPesq protocol number 624/2005). A total of 467 pregnant women from public hospitals of São Paulo, Brazil were submitted to amniocentesis under ultrasound guidance during the second trimester (14-25 weeks of gestation, corresponding to probable seroconversion taking place between the $10^{\text {th }}$ and $21^{\text {st }}$ weeks). Inclusion criteria were based on the serological evidence of recent Toxoplasma infection (presence of positive IgM and significant titers of IgG anti-Toxoplasma, evaluated by means of commercial immuno-enzymatic or immunoquimioluminescent tests or immuno-fluorimetry, depending on the local availability). Exclusion criteria included inadequate amniotic fluid samples either by the mixture with blood or meconium or sample insufficiency (less than $5 \mathrm{ml}$ of amniotic fluid collected from the $14^{\text {th }}$ week). Of the 467 patients, $388(83.08 \%)$ were on spiramicin and $79(16.92 \%)$ were on sulfadiazine therapy, which began immediately after diagnostic serology, performed with commercial kits ${ }^{15} 1$ to 6 weeks before amniocentesis. The decision regarding the prescription of either spiramicin or sulfadiazine was made on the basis of gestational age, i.e., those who started treatment before the $18^{\text {th }}$ week received spiramicin and, in the minority of cases, sulfadiazine was used after the $18^{\text {th }}$ week. Patients were informed of amniocentesis risks and the nucleic acid procedures and consented with all subsequent testing.

DNA EXTRACTION, AMPLIFICATION AND DETECTION: DNA from amniotic fluid samples was obtained according to a previously described salting-out protocol $^{16}$. DNA concentration was estimated by means of UV spectrophotometry at $260 \mathrm{~nm}$ (DU-70, Beckman). PCR assays were performed in $50 \mu \mathrm{LL}$ of total volume (MJ Research PT-150 minicycler) containing approximately $100 \mathrm{ng}$ of genomic DNA from amniotic fluid samples, $100 \mathrm{mM}$ Tris- $\mathrm{HCl}$ and $500 \mathrm{mM} \mathrm{KCl,} 2.5$ units of Taq DNA polymerase (Amersham Biotech, USA), $200 \mu \mathrm{M}$ dNTP (Invitrogen, USA), $1.5 \mathrm{mM} \mathrm{MgCl}_{2}$ and $0.4 \mu \mathrm{M}$ for each of the primers (IDT- synthesized by Prodimol, Belo Horizonte, Brazil). The PCR products were detected in $2 \%$ ethidium-bromide-stained agarose gels (Sigma, USA) or 2:1 nusieve-agarose gels (FMC - Sigma) in a horizontal electrophoresis apparatus (Horizon H58, Life Technologies, USA). In each experiment, a negative control composed of either sterile water instead of genomic DNA or DNA from a non-infected individual was tested. A positive control was also employed (Toxoplasma gondii RH strain DNA). Prior to specific Toxoplasma amplifications, all DNA samples were amplified with $\beta$-actin primers ${ }^{17}$ to ensure the inexistence of amplification inhibitors. The amplification parameters of the PCR systems are described in table 1.

\section{RESULTS}

A total of 467 women, aged 18-35 years, were enrolled in the present study. All had seroconverted during the late first or early second trimester, $321(66.8 \%)$ were in their second pregnancy and $299(64.0 \%)$ had a fetal ultrasound examination. Only three women (1.0\%) presented abnormalities, according to the attendant physicians. AntiToxoplasma $\mathrm{IgG}$ avidity tests were reported in only 32 women $(6.85 \%)$, and tests were performed with four different in-house methods, showing eight patients with low avidity, 12 with high avidity IgG samples and 12 inconclusive tests (with a recommendation to repeat the test after two weeks).

One-round amplifications. The $\beta$-actin fragment was amplified from all 467 DNA samples from the amniotic fluid specimens, thus confirming the lack of inhibitors. Of the specific Toxoplasma DNA amplifications, 189 (40.5\%) samples were positive for at least one of the one-round PCR systems: $120 / 189$ (63.5\%) for the B1 gene, 24/189 for AF146527 (12.7\%) and 45/189 (23.8\%) for both B1 and AF146527. None of the samples were positive for rDNA (0/189).

Nested-B1-PCR. Fifty of the 278 amniotic fluid samples that had negative results in the three one-round PCRs were 
Table 1 - Description of the four PCR systems used in the present study

\begin{tabular}{|c|c|c|c|c|c|}
\hline Target gene & Primer composition & Annealing & Cycles & Amplicon & Reference \\
\hline B1 & $\begin{array}{l}\text { JW } 63 \text { - sense } \\
\text { 5'-GCACCTTTCGGACCTCAACAACCG-3' } \\
\text { JW } 62 \text { - anti-sense } \\
\text { 5'- TTCTCGCCTCATTTCTGGGTCTAC-3' }\end{array}$ & $55^{\circ} \mathrm{C}$ & 40 & $286 \mathrm{bp}$ & Pelloux et al. ${ }^{18}$ \\
\hline rDNA & $\begin{array}{l}\text { rtg1- sense } \\
\text { 5'- GGCATTCCTCGTTGAAGATT-3' } \\
\text { rtg2 - anti-sense } \\
\text { 5'- CCTTGGCCGATAGGTCTAGG-3' }\end{array}$ & $58^{\circ} \mathrm{C}$ & 40 & $88 \mathrm{bp}$ & Bretagne et al. ${ }^{7}$ \\
\hline AF146527 & $\begin{array}{l}\text { AF146527 - sense } \\
\text { 5'- CTGCAGGGAGGAAGACGAAAGTT-3' } \\
\text { AF146527- anti-sense } \\
\text { 5'- CTGCAGACACAGTGCATCTGGAT-3' }\end{array}$ & $55^{\circ} \mathrm{C}$ & 40 & $529 \mathrm{bp}$ & Homan et al. ${ }^{19}$ \\
\hline \multirow[t]{2}{*}{ B1 (nested) } & $\begin{array}{l}\text { JW } 63 \text { - sense (first round) } \\
\text { 5'-GCACCTTTCGGACCTCAACAACCG-3' } \\
\text { JW } 62 \text { - anti-sense (first round) } \\
\text { 5'- TTCTCGCCTCATTTCTGGGTCTAC-3' }\end{array}$ & $55^{\circ} \mathrm{C}$ & 40 & $286 \mathrm{bp}$ & Pelloux et al. ${ }^{18}$ \\
\hline & $\begin{array}{l}\text { B22m - } 2^{\text {nd }} P C R \text { - sense (second round) } \\
\text { 5'- AACGGGCGAGTAGCACCTGAGGAGA-3' } \\
\text { B23m - 2 } 2^{\text {nd } P C R ~-~ a n t i-s e n s e ~(s e c o n d ~ r o u n d) ~} \\
\text { 5'-TGGGTCTACGTCGATGGCATGACAACT-3' }\end{array}$ & $62^{\circ} \mathrm{C}$ & 25 & $115 \mathrm{bp}$ & Hohlfeld et al. ${ }^{6}$ \\
\hline
\end{tabular}

chosen by computer-assisted randomization analysis ${ }^{(20)}$ (www. random.org) and were re-tested by a nested PCR, targeting the B1 gene. Random numbers are useful for a variety of purposes, including the selection of random samples from larger data sets. This double-round amplification detected nine additional positive cases (9/50 or $18 \%$ ).

\section{DISCUSSION}

This study has limitations due to the lack of clinical data, accurate serological results (in particular, an IgG avidity test) and high-quality descriptions of fetal ultrasound abnormalities. In a recent study, ${ }^{21} 553$ serum samples from pregnant women whose dates of infection had been determined as well as 50 samples from immunosuppressed patients were tested for IgG avidity by means of a novel immunoassay. The authors concluded that this novel avidity test (Vidas) was helpful in ruling out that infection had occurred within the past four months. Unfortunately, the anti-Toxoplasma $\mathrm{IgG}$ avidity test was reported in a minority of 32 patients $(6.85 \%)$ in our study, invalidating efforts to analyze our data with respect to the literature.

Another point that merits discussion is the follow-up of newborns until the age of 12 months with repeated anti-T. gondii $\operatorname{IgM}$ and IgG measurements. Although this procedure is highly recommended, these measurements were obtained in only 84 children belonging to the first part of the study. Nevertheless, the 467 amniotic fluid samples reported here constitute the most representative South American cohort analyzed thus far, although the only inclusion criterion adopted in our study was the documentation of seroconversion to $T$. gondii during pregnancy.

There is a general concern regarding the significant variability found in amplification systems used to detect Toxoplasma gondii DNA in different types of biological samples. Guy et al. (1996) ${ }^{22}$ performed a multi-center study comprised of five European centers that reported amniotic fluid samples containing limiting dilutions of tachyzoites that varied from 10 to zero. They reported a lack of positive sample detection as well as false positives. In another European multi-center study involving fifteen laboratories, Pelloux et al. (1997) ${ }^{23}$ concluded that there was great heterogeneity among PCR protocols and comparative performances, as only nine of the fifteen laboratories succeeded in amplifying the equivalent of one parasite, two were unable to detect any of the positive samples, and four laboratories had false-positive results. More recently, Kaiser et al. $(2007)^{24}$ studied the performance of 33 laboratories from 17 different countries. Only $42.1 \%$ of the samples were correctly identified, while two or more mistakes occurred in $36.8 \%$ of the centers. The lowest parasite concentration, corresponding to five tachyzoites, was not identified by $39.5 \%$ of the laboratories. In-house techniques were used in $84.2 \%$ of the laboratories, and a commercial kit was used in the remaining $15.8 \%$. False-positive results occurred in two laboratories (6.06\%).

Because amplification techniques used to detect Toxoplasma DNA by PCR are not standardized and because 
there is no consensus on the best protocol to use, ${ }^{6-13,15}$ the present study has evaluated the performance of three one-round amplification systems (B1 gene, AF146527, rDNA) to detect Toxoplasma gondii DNA in 467 amniotic fluid samples. A total of 189 samples (40.47\%) yielded positive results using at least one of the three one-round PCR systems, which is in agreement with the expected transmission rate during the second trimester of gestation. ${ }^{15}$ It is also important to note that the majority of the primers used in our study are among the most tested in the literature, in particular, the B22/B23 primers for the B1 gene.

According to previous studies, the three one-round PCR systems employed are able to detect the equivalent of one to ten parasites, ${ }^{6,7,18,19}$ a finding confirmed in our facilities in spiked samples and limiting dilution series. A second round of amplification should therefore not be necessary in order to attain an adequate sensitivity. Results of the first part of our study, however, have suggested the opposite. The three amplification systems employed, even though they were targeting repetitive sequences (rDNA has hundreds of copies in one parasite genome, AF146527 has between 200 and 300 copies and the B1 gene has 35 copies per genome), showed significant performance differences and inadequate sensitivity (only 78.6\%) when using clinical, ophthalmologic, radiological and serological follow-up of 84 children (from PCR-positive pregnancies) until the age of 12 months $^{25}$ as diagnostic criteria. Unfortunately, we did not have access to data concerning the other 383 cases, because either the mothers gave birth in different hospitals or the neonates were included in other studies.

It is important to note that the rDNA PCR did not succeed in amplifying any of the 467 amniotic fluid samples tested, although this method has been employed in previous studies carried out in our laboratory to diagnose cases of ocular toxoplasmosis and congenital infection (data not shown). The use of a nested-B1-PCR increased the sensitivity in the present study, as we found nine additional positive cases among the 278 initially negative one-round PCRs. This indicates that although theoretically not necessary, a second round of amplification can be helpful, especially when treated patients are being evaluated ${ }^{2}$. These results are most likely due to a reduction in parasite burden.

Although it is logical that a nested amplification should always be more sensitive than one-round systems and that the detection should be more sensitive for more repetitive DNA sequences, a series of studies have found discordant results. Homan et al. ${ }^{19}$ described the AF146527 sequence, which is repeated 200-300 times, reporting that amplification systems derived from AF146527 were more sensitive than those of the B1 gene. Our results were inconsistent with these findings. Jones et al. ${ }^{8}$ analyzed aqueous humor samples by means of three different PCR systems with primers for the B1 gene, SAG1 and rDNA. The first two systems were nested amplifications, whereas the rDNA PCR was a oneround PCR. They concluded that the B1 gene PCR was more sensitive than the other two amplification systems, which is consistent with our results, although we did not test SAG1. Filisetti et al. ${ }^{10}$ analyzed 83 samples from 44 newborns with suspicion of congenital toxoplasmosis by means of rDNA, B1 gene and AF146527 amplification. Unlike our study, they concluded that the three systems were equivalent and, surprisingly, that they were not more sensitive than the isolation of the parasite after mice inoculation. Buchbinder et al. ${ }^{9}$ analyzed 11 patients with congenital toxoplasmosis by means of real time PCR with primers for the B1 gene and SAG1. They were able to detect the equivalent of 10 parasites and concluded that the two systems were equally sensitive. Jalal et al. ${ }^{12}$ tested eight amniotic fluid samples, two CSF samples, four vitreous humor samples and six biopsies. The amplification systems tested were based on the B1 gene using one-round PCR, or nested amplification followed by hybridization in microtitration plaques (enzyme immunoassay). Unlike our study, they found that it was not beneficial to perform a nested amplification or a PCR followed by hybridization because there was no sensitivity gain. In an interesting report, Chabbert et al. ${ }^{11}$ tested two amplification systems using two different sets of primers, both for the B1 gene (B22/B23 and T1-T4). They concluded that the B22/23 system was more sensitive than the T1-T4 system, even though all of the primers were chosen within the B1 gene sequence. In our study, we also used the socalled "more sensitive B1 gene primers" B22/B23 in the nested amplification and have corroborated the sensitivity gain. More recently, Nagy et al. ${ }^{13}$ analyzed 64 amniotic fluid samples using four different amplification methods: one conventional PCR, one PCR-RFLP, and two real time PCR systems with different detection methods. Although they claimed that the two real time PCR systems were the most sensitive, they concluded that all four systems were able to detect as few as five parasites and were therefore considered to be suitable for molecular diagnosis of congenital infections.

Finally, HLA-class II genes may modify the outcome of Toxoplasma gondii infection ${ }^{1}$ in hosts with different genetic features. With respect to parasites, atypical or recombinant genotypes among Toxoplasma isolates from different countries and continents leading to DNA polymorphisms at the exact site of primer-target DNA hybridization could also decrease amplification performance. This heterogeneity might occur between Toxoplasma isolates infecting humans and animals in Brazil as well as other South American countries ${ }^{14,26-29}$ and could at least partially explain why 
the B1 gene PCR was significantly more sensitive than the AF146527 system in the present study. and the most repetitive sequence, the rDNA, did not amplify any of the 467 amniotic fluid samples tested. Further studies are needed to determine whether Brazilian women are genetically distinct from other populations as well as whether Toxoplasma gondii genotypes of amniotic fluid samples in
Brazil are different from those described in Europe, USA and other South American countries.

We conclude that the use of PCR for the diagnosis of fetal Toxoplasma infection in Brazil should be targeted to the B1 gene when limited to only one gene, preferably by nested amplification with the B22/B23 primers.

\section{REFERENCES}

1. Mack DG, Johnson JJ, Roberts F, Roberts CW, Estes RG, David C, et al. HLA-class II genes modify outcome of Toxoplasma gondii infection. Int J Parasitol. 1999;29:1351-8.

2. Thulliez P. Commentary: efficacy of prenatal treatment for toxoplasmosis: a possibility that cannot be ruled out. Int J Epidemiol. 2001;30(6):1315-6.

3. Frenkel JK, Ambroise-Thomas P. Genomic drift of Toxoplasma gondii. Parasitol Res. 1997;83:1-5.

4. Howe DK, Sibley LD. Toxoplasma gondii comprises three clonal lineages: correlation of parasite genotype with human disease. J Infect Dis. 1995;172:1561-6.

5. Guo Z-G, Gross U, Johnson AM. Toxoplasma gondii virulence markers identified by random amplified polymorphic DNA polymerase chain reaction. Parasitol Res. 1997;83: 458-63.

6. Hohlfeld P, Daffos F, Costa JM, Thulliez P, Forestier F, Vidaud M. Prenatal diagnosis of congenital toxoplasmosis with a PolymeraseChain-Reaction test on amniotic fluid. N Engl J Med. 1994;15:695-9.

7. Bretagne S, Costa J-M, Fleury-Feith J, Poron F, Debreuil-Lemaire M-L, Vidaud M. Quantitative competitive PCR with bronchoalveolar lavage fluid for diagnosis of toxoplasmosis in AIDS patients. J Clin Microbiol. 1995;33:(6):1662-4.

8. Jones CD, Okhravi N, Adamson P, Tasker S, Lightman S. Comparison of PCR detection methods for B1, P30 and 18S rDNA genes of T. gondii in aqueous humor. Invest Ophtalmol Visual Sci. 2000;41(3):634-44.

9. Buchbinder S, Blatz R, Rodloff AC. Comparison of real-time PCR detection methods for B1 and P30 genes of Toxoplasma gondii. Diagn Microbiol Infect Dis. 2003;45:269-71.

10. Filisetti D, Gorcii M, Pernot-Marino E, Villard O, Candolfi E. Diagnosis of congenital toxoplasmosis: comparison of targets for detection of Toxoplasma gondii by PCR. J Clin Microbiol. 2003;41(10):4826-8.

11. Chabbert E, Lachaud L, Crobu L, Bastien P. Comparison of two widely used PCR primer systems for detection of Toxoplasma in amniotic fluid, blood and tissues. J Clin Microbiol. 2004;42(4):1719-22.

12. Jalal S, Nord CE, Lappalainen M, Evengard B \& ESCMID Study Group on Toxoplasmosis. Rapid and sensitive diagnosis of Toxoplasma gondii infections by PCR. Clin. Microbiol. Infect. 2004;10(10):937-9.
13. Nagy B, Ban Z, Beke A, Nagy GR, Lazar L, Papp C, et al. Detection of Toxoplasma gondii from amniotic fluid, a comparison of four different molecular biological methods. Clin Chim Acta. 2006;368(1-2):131-7.

14. Gallego C, Saavedra-Matiz C, Gómez-Marín JE. Direct genotyping of animals and human isolates of Toxoplasma gondii from Colombia (South America). Acta Trop. 2006; 97(2):161-7.

15. Montoya JG, Remington JS. Management of Toxoplasma gondii infection during pregnancy. Clin Infect Dis. 2008;47:554-66.

16. Miller AS, Dykes DD, Polesky HF. A simple salting out procedure for extracting DNA from human nucleated cells. Nucleic Acids Res. $1988 ; 16(3): 1215$

17. Nakajima-Iijima S, Hamada H, Reddy P, Kakunaga T. Molecular structure of the human cytoplasmic beta-actin gene: interspecies homology of sequences in the introns. Proc Natl Acad Sci. 1985;82:6133-7.

18. Pelloux H, Dupouy-Camet J, Derouin F, Alboulker J-P, Raffi F. A multicentre prospective study for the polymerase chain reaction detection of Toxoplasma gondii DNA in blood samples from 186 AIDS patients with suspected toxoplasmic encephalitis. Bio-Toxo Study Group. AIDS. 1997;11(15):1888-90.

19. Homan WL, Vercammen M, De Braekeleer J, Verschueren H. Identification of a 200 to 300 -fold repetitive $529 \mathrm{bp}$ DNA fragment in Toxoplasma gondii, and its use for diagnostic and quantitative PCR. Int J Parasitol. 2000;30:69-75.

20. Beller EM, Gebski V, Keech AC. Randomisation in clinical trials. Med J Aust 2002; 177(10):565-7.

21. Fricker-Hidalgo H, Saddoux C, Suchel-Jambon AS, Romand S, Foussadier A, Pelloux H, et al. New Vidas assay for Toxoplasmaspecific IgG avidity: evaluation on 603 sera. Diagn Microbiol Infect Dis. 2006;56(2):167-72.

22. Guy EC, Pelloux H, Lappalainen M, Aspöck H, Hassl A, Melby KK, et al. Interlaboratory comparison of polymerase chain reaction for the detection of Toxoplasma gondii DNA added to samples of amniotic fluid. Eur J Clin Microbiol Infect Dis. 1996;15 (10):836-39.

23. Pelloux H, Guy E, Angelici MC, Aspöck H, Bessières MH, Blatz R, et al. A second European collaborative study on polymerase chain reaction for Toxoplasma gondii, involving 15 teams. FEMS Microbiol Lett. 1998;165(2):231-7. 
24. Kaiser K, Van Loon AM, Pelloux H, Ferrandiz J, Picot S, Wallace P, et al. Multicenter proficiency study for detection of Toxoplasma gondii in amniotic fluid by nucleic acid amplification methods. Clin Chim Acta. 2007;375(1-2):99-103.

25. Andrade F, Amorim S, Hisaba W, Cordioli E, Okay T, Amero E, et al Diagnosis of congenital Toxoplasma gondii infection by polymerase chain reaction (PCR) on amniotic fluid samples. Ultrasound Med Biol. 2002;20(1):29.

26. Vallochi AL, Muccioli C, Martins MC, Silveira C, Belfort R Jr, Rizzo LV. The genotype of Toxoplasma gondii strains causing ocular toxoplasmosis in humans in Brazil. Am J Ophthalmol. 2005;139(2):350-1.
27. Ferreira AM, Vitor RW, Gazinelli RT, Melo MN. Genetic analysis of natural recombinant Brazilian Toxoplasma gondii strains by multilocus PCR-RFLP. Infect Genet Evol. 2006;6(1):22-31.

28. Peyron F, Lobry JR, Musset K, Ferrandiz J, Gomez-Marin JE, Petersen E, et al. Serotyping of Toxoplasma gondii in chronically infected pregnant women: predominance of type II in Europe and types I and III in Colombia (South America). Microbes Infect. 2006;8(9-10):2333-40.

29. Ferreira IM, Vidal JE, Costa-Silva TA, Meira CS, Hiramoto RM, Penalva de Oliveira AC, et al. Toxoplasma gondii: genotypes of strains from Brazilian AIDS patients with cerebral toxoplasmosis by multilocus PCR-RFLP markers. Exp Parasitol. 2008;118(2): 221-7. 